\title{
Psicologia Positiva e bem-estar docente: Estado de Conhecimento (CAPES, 2011-2012)*
}

\author{
Jordana Wruck Timma \\ Claus Dieter Stobäus ${ }^{b}$ \\ Juan José Moriño Mosquerac
}

\section{Editor}

Maria Inês Côrte Vitoria

PUCRS, RS, Brasil

\section{Equipe Editorial}

Pricila Kohls dos Santos

PUCRS, RS, Brasil

Marcelo Oliveira da Silva

PUCRS, RS, Brasil

Carla Spagnolo

PUCRS, RS, Brasil

Rosa Maria Rigo

PUCRS, RS, Brasil

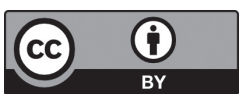

A matéria publicada neste periódico é licenciada sob forma de uma Licença Creative Commons - Atribuição 4.0 Internacional.

RESUMO: São variadas as situações que afetam docentes em aspectos pessoais e profissionais, causando o denominado mal-estar docente, levando até a um estado de estresse ou mesmo esgotamento, destacando-se, entre eles: indisciplina discente, falta de qualificação, remuneração, gestão de tempo, tempo de preparo de atividades, entre outros. Como contraponto pode-se trabalhar em direção ao bem-estar docente, levando-se em conta propostas da Psicologia da Saúde e da Psicologia Positiva, antecipando-se ao mal-estar com medidas preventivas. O estudo levou em conta material bibliográfico (Teses e Dissertações) disponibilizado em forma digital no Banco de Teses da CAPES, com o que pode-se construir um referencial que aborda aspectos referentes à Psicologia Positiva e ao bem-estar docente, bem como a relação entre ambos. Vale destacar que se trata de um estado de conhecimento sobre a temática, com base nos dois anos disponibilizados no referido banco. Após essa busca, foi realizada leitura flutuante dos textos selecionados. Como comentários finais destacam-se bons resultados com a aplicação mormente quando se atua de modo preventivo, sendo que Psicologia da Saúde e Psicologia Positiva conectam-se bem à Educação, tanto para docentes como para discentes.

Palavras-chave: Estado de Conhecimento. Banco de Teses CAPES. Psicologia Positiva. Bem-estar docente. 2011-2012.

* Uma prévia deste texto foi apresentada em mesa redonda no 1 Simpósio Latino Brasileiro de Psicologia Positiva, que ocorreu nos dias 22 e 23 de março de 2014, em Foz do Iguaçu (com parceria de Magda Altafini Gomes, Claus Dieter Stobaus e Juan José Moriño Mosquera). Essa mesma prévia será publicada na revista organizada por parte da equipe organizadora do evento (Revista Latino Americana de Psicologia Positiva). Para o evento, a prévia consistia no estado de conhecimento do ano 2012 (único disponível naquele momento) e em dados mais empíricos. O que aqui apresento não se trata apenas de um texto maior em relação ao número de páginas, mas um texto com maior aprofundamento na pesquisa de estado de conhecimento nos dois anos atualmente disponíveis pela CAPES (2011 e 2012) e, também, com maior aprofundamento teórico. Vale acrescentar, que o presente texto também é fruto das discussões na disciplina "Construindo o Estado de Conhecimento de sua Dissertação/Tese", ministrada pela professora Dra. Marília Costa Morosini, no PPGE-PUCRS.

a Doutoranda e Mestre em Educação (PUCRS; UCS); Psicopedagoga. Bolsa CAPES. E-mail: <jordanawruck@hotmail.com>.

b Pós-doutor em Psicologia (UAM/ES); Professor titular da Faculdade de Educação (PUCRS e LASALLE).

c Pós-doutor em Psicologia (UAM/ES); Professor titular da Faculdade de Educação e de Letras (PUCRS). 
ABSTRACT: They are different situations that affect teachers in personal and professional aspects, causing the so-called teacher malaise, leading to a state of stress or even burnout, highlighting, among them: student indiscipline, lack of qualifications, remuneration, time management, preparation time activities, among others. As a counterpoint can work toward teacher welfare, taking into account the Health Psychology and Positive Psychology proposals, anticipating the unease with preventive measures. The study took into account bibliography (Theses and Dissertations) available in digital form on Bank CAPES thesis, with which one can build a framework that addresses issues related to Positive Psychology and teaching well-being as well as the relationship between them. It is worth noting that it is a state of knowledge on the subject, based on two years provided in said bank. After this search, superficial reading of selected texts was performed. As final comments stand out with good results especially when the application acts in a preventive way, and Health Psychology and Positive Psychology connect well to education, both for teachers and for students.

Keywords: State of Knowledge. CAPES Thesis Database. Positive Psychology. Faculty welfare. 2011-2012.

\section{Considerações iniciais}

Convém destacar que esse nosso trabalho teve início nos debates de que participamos no grupo de pesquisa "Bem e mal-estar docente", na FACED-PUCRS, já há algum tempo, resultando em várias produções acadêmicas.

Bem diz Paula (2007) que, comumente (e erroneamente), o trabalho docente tem sido associado à vocação, idealismo e solidariedade, minimizando seu exercício, como se o objetivo pela escolha da profissão fosse o bem social emergente da formação e educação das pessoas, não importando os recursos econômicos advindos de seu trabalho. Obviamente, que o bem social advindo da formação e educação das pessoas tem muita relevância, aliás, é promotor de orgulho pela profissão que exerce, no entanto, nenhuma pessoa consegue sustento apenas por orgulho, professores não são diferentes e precisam organizar-se econômica e financeiramente para que possam se manter.

Iniciamos com essa premissa, alertando para um dos fatores que vem sendo motivo de estresse pelos professores: sua desvalorização. É importante trabalhar no que se gosta, mas assumir tantas responsabilidades como docente pode comprometer seu desempenho. O que justifica o nosso trabalho é que são muitas e variadas as situações que afetam docentes em seus aspectos pessoais e profissionais, causando mal-estar docente, levando ao estresse/esgotamento. Entre essas muitas e variadas situações estão a indisciplina discente, a falta de qualificação, a baixa remuneração, a difícil gestão de tempo, o pouco tempo de preparo de atividades. Como contraponto, pode-se trabalhar em direção 
ao bem-estar docente, com propostas da Psicologia da Saúde e da Psicologia Positiva, antecipando-se ao mal-estar com medidas preventivas.

Nesse sentido, vale destacar a defesa de Paula (2007, p. 27, grifos da autora) em consonância com a "ideia proposta pela Organização Mundial da Saúde de que 'estar saudável não é o mesmo que não estar enfermo' a saúde passa a ser esse estado de bem-estar físico, emocional, mental e social" e, a partir disso, a pessoa passa a sentir-se capaz de desenvolver suas potencialidades, resultando em prol de uma indiscutivelmente relevante função social, como, por exemplo, o ato e a arte de educar.

Descrevemos brevemente alguns fatores causadores de mal-estar docente como forma de situar a temática, focando principalmente no bem-estar e saúde do professor, via Psicologia Positiva, de como pode ser aplicada à Educação, quando direcionada à pessoa do docente, de como pode ser promotora de bem-estar; e verificando como pode auxiliar na prevenção.

Nosso estudo levou em conta Teses e Dissertações disponibilizadas digitalmente no Banco de Teses da CAPES, com o que se pôde construir um referencial abordando Psicologia Positiva e bem-estar docente. Como método, foi realizada leitura flutuante dos resumos no site do Banco de Teses da CAPES, em que se verificou com palavras-chave Psicologia Positiva e Bem-estar-docente, mormente nas defendidas em Programas de Pós-Graduação em Educação, encontrando cento e oitenta e um trabalhos para a palavra-chave Psicologia Positiva (cem defendidos em 2012 e oitenta e um em 2011) e vinte e quatro trabalhos para a palavra-chave bem-estar docente (onze em 2012 e treze em 2011), destacando que apenas os trabalhos defendidos nesses dois anos (2012 e 2011), já que o banco está passando por reformulações.

Dos 181 trabalhos, apenas sete foram defendidos em Programas de Pós-Graduação em Educação; dos outras vinte e quatro, quatorze foram defendidas em Programas de Pós-Graduação em Educação. Dos sete trabalhos encontrados com o descritor "psicologia positiva", dois tem relação com a temática da pesquisa, sendo que um deles parece repetido na busca com o outro descritor que utilizamos para o presente texto. Dos quatorze trabalhos encontrados com o descritor "bem-estar docente", dez tem relação com a temática da pesquisa. Portanto, no total, onze trabalhos foram analisados (um da psicologia positiva, nove do bem-estar docente e um que aparece nos dois descritores). Notamos que o termo Psicologia Positiva é mais utilizado em programas de Psicologia, enquanto bem-estar é mais utilizado nos da Educação. Os gráficos a seguir contribuem para visualização da distribuição por áreas.

Os Gráficos 1 e 2 nos permitem ver o panorama das pesquisas defendidas nas mais distintas áreas, entretanto vale destacar que nosso foco ficou naquelas defendidas em programas em Educação e com relação com a temática proposta, todas em nível de Mestrado (a maioria delas na PUCRS). A categoria "outros" é relacionada a teses e dissertações defendidas em pequenos números (um ou dois) em distintos programas. 
Gráfico 1 - Palavra-chave Psicologia Positiva

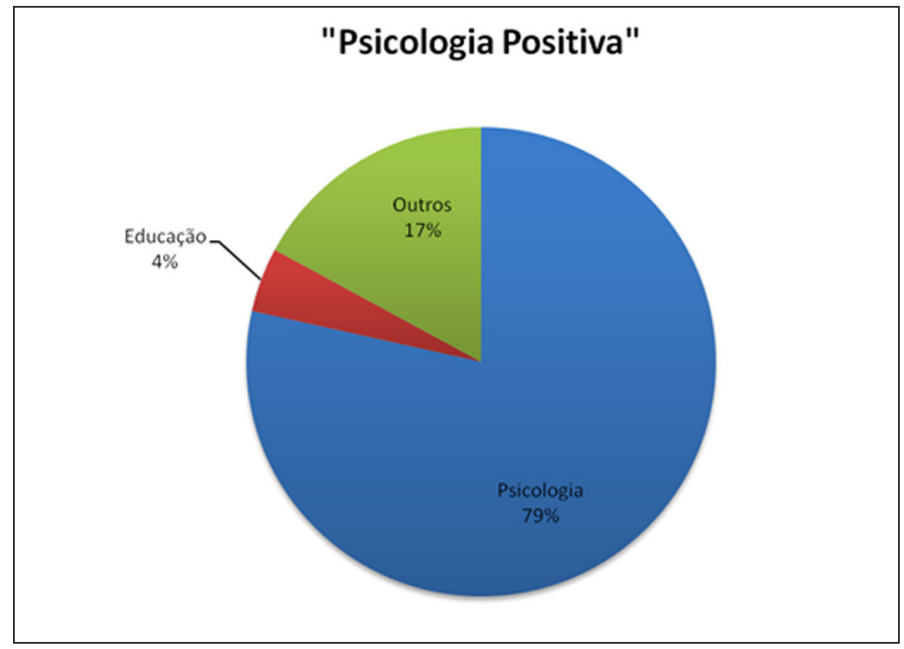

Fonte: os autores (dados disponibilizados no Banco de Teses e Dissertação da CAPES).
Gráfico 2 - Palavra-chave Bem-estar docente

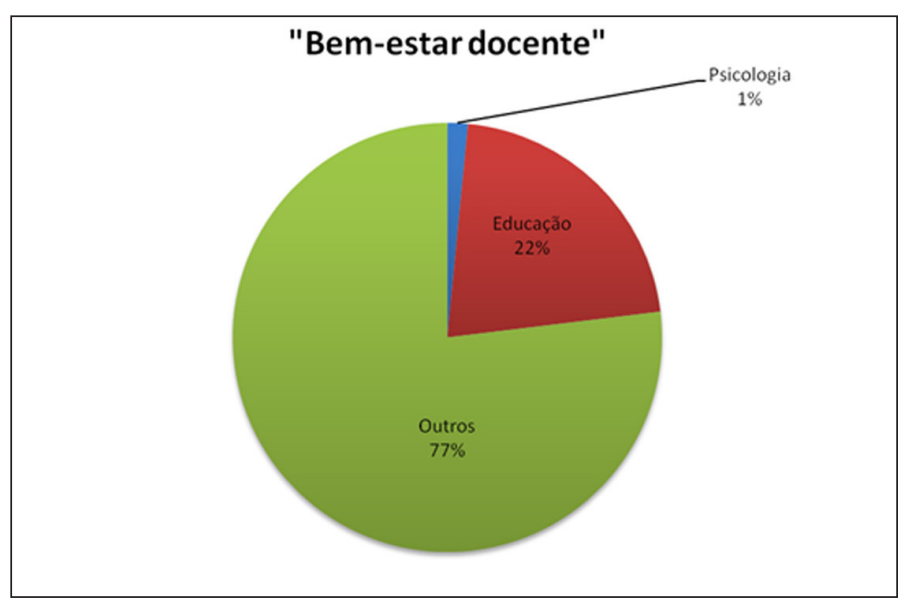

Fonte: os autores (dados disponibilizados no Banco de Teses e Dissertação da CAPES).

Os trabalhos analisados podem ser conferidos no Quadro 1 a seguir. 
Quadro 1 - Trabalhos analisados

\begin{tabular}{|l|l|}
\hline \multicolumn{1}{|c|}{ Título } & \multicolumn{1}{|c|}{ Autoria } \\
\hline Estudantes universitários com dificuldades de aprendizagem: como motivá-los & Altafini(2012) - PUCRS \\
\hline $\begin{array}{l}\text { Grupo de sensibilização e criatividade: espaço de retomada de bem-estar/autoimagem/autoestima } \\
\text { de educadores }\end{array}$ & Castilhos (2011) - PUCRS \\
\hline $\begin{array}{l}\text { Níveis de mal-bem-estar docente, de autoimagem e autoestima e de autorrealização de docentes } \\
\text { em uma escola tradicional de Porto Alegre }\end{array}$ & Dohms (2011) - PUCRS \\
\hline $\begin{array}{l}\text { Educação física nas séries iniciais: uma proposta de bem-estar para unidocentes do município de } \\
\text { Alegrete-RS }\end{array}$ & Guterres (2011) - PUCRS \\
\hline Bem-estar e mal-estar dos professores no Colégio Marista Pio XIl de Novo Hamburgo - RS & Kehl (2011) - PUCRS \\
\hline O bem-estar na escola salesiana: evidências da realidade & Pinheiro (2011) - PUCRS \\
\hline Saúde docente: uma realidade detectada - em direção ao bem-estar e a realização profissional & Mendes (2011) - PUCRS \\
\hline $\begin{array}{l}\text { A influência da gestão escolar no bem-estar docente: percepções de professores sobre líderes } \\
\text { educacionais de uma escola particular de Porto Alegre }\end{array}$ & Santos (2012) - PUCRS \\
\hline Do mal-estar ao bem-estar docente: uma análise de caso Argentina e Brasil & Senna (2011) - PUCRS \\
\hline $\begin{array}{l}\text { Atividades artísticas com teor terapêutico e suas contribuições para a compreensão das } \\
\text { inquietações do ser humano professor }\end{array}$ & Wandscheer (2012) - UNOESC \\
\hline Bem-estar docente: um estudo em escolas públicas de Porto Alegre & Zacharias (2012) - PUCRS \\
\hline
\end{tabular}

Fonte: Os autores, com base nas pesquisas defendidas em 2012 e 2011 e que estão disponibilizadas no Banco de Teses e Dissertação da CAPES.

\section{Conceitos emergentes}

Psicologia Positiva - A partir da proposta de Seligman (2011), a Psicologia Positiva é uma área da psicologia que trabalha com as potencialidades e virtudes humanas, sendo seu enfoque salugênico (ao contrário da psicologia tradicional, que tem seu enfoque na patogenia).

No entanto, de acordo com Portella (2013) isso não significa que a Psicologia Positiva condene o restante da psicologia, pelo contrário. A Psicologia Positiva não tem por objetivo negar o que tem de ruim, o que não vai bem, as doenças ou demais aspectos desagradáveis que podem acontecer na vida. "A Psicologia Positiva reconhece a 
existência do sofrimento humano, situações de risco e patologias, no entanto, não está restrita apenas a reparar o que há de errado ou o ruim, mas (re)construir qualidades positivas" (PORTELLA, 2013, p. 23). Para a autora (2013), o tratamento psicológico e as pesquisas deveriam, também, fomentar e nutrir aquilo que existe de melhor nas pessoas. Em outra obra sua (2014, p. 42), a autora defende que o objetivo da psicologia Positiva é "[...] investigar e trabalhar com os fatores que dão significado ao que há de sadio no ser humano".

Bem-estar docente - na Enciclopédia de Pedagogia Universitária (MOROSINI, 2006, p. 373), esse termo está definido da seguinte forma:

Bem-Estar na Docência: diz respeito à própria motivação e realização do professor, quer na dimensão pessoal, quer na dimensão profissional. Dois momentos existenciais respondem por níveis mais elevados de bem-estar: formação docente e sentido profissional (MOSQUERA e STOBÄUS, 2000). No primeiro, evitar uma relação estritamente normativa; não estabelecer falsos ideais; abandonar a ambigüidade pedagógica, salientar o conhecimento da realidade cultural. No segundo, valorizar o trabalho docente pelo saber e pela competência. (MOSQUERA; STOBÄUS)

Inicio pelo conceito de bem-estar docente que, de acordo com Jesus (2007, p. 26-27), pode ser compreendido pela motivação e pela realização do profissional professor “[...], em virtude do conjunto de competências (resiliência) e de estratégias (coping) que este desenvolve para conseguir fazer frente às exigências e dificuldades profissionais, superando-as e otimizando o seu próprio funcionamento". Posteriormente, Jesus e Rezende (2009, p. 17) afirmam que esse conceito é "resultado da orientação geral positiva do sujeito para os acontecimentos de vida". E, que "a sensação de bem-estar é fruto de um equilíbrio entre as possibilidades e os desejos, entre as capacidades e as necessidades" (HUÉ, 2008, p. 156). Para esse autor, o bem-estar e a alegria implicam no profissional em seu trabalho e na relação com as pessoas com quem o exerce.

Apenas para explicitar, quando se fala no contrário, no conceito de mal-estar na docência, de acordo com Esteve (1994, p. 24-25), estamos tratando de um conceito que serve para “[...] descrever os efeitos permanentes de caráter negativo que afetam a personalidade do professor como resultado das condições psicológicas e sociais em que se exerce a docência”. Já para Stobäus, Mosquera e Santos (2007, p. 263) o mal-estar entre professores, pode ser como uma "doença social que provoca a pessoa e é causado pela falta de apoio da sociedade aos professores, tanto no terreno dos objetivos de ensino, como nas compensações materiais e no reconhecimento do status que se lhes atribui". 


\section{O bem e o mal-estar docente e a Psicologia Positiva}

Bem-estar não exclui mal-estar, é indissociável falar num e não pensar no outro, pois são lados ao mesmo tempo distintos e complementares da mesma moeda, assim como a psicologia mais tradicional tem enfoque mais na patologia/doença e a Psicologia Positiva tem enfoque mais salugênico/saúde, no sentido de lembrar mais a prevenção ou atuação em favor do bem-estar. Como bem ressalta Portella (2013, p. 21), "a Psicologia preocupou-se em estudar e pesquisar o lado 'negro' do ser humano, isto é, a doença, os defeitos, fraquezas, falhas e dificuldades humanas”, em contraponto ela foi negligenciando "os aspectos saudáveis (forças, qualidades, virtudes, talentos, pontos fortes, valores e crenças funcionais, emoções positivas, engajamento, metas, relações sociais saudáveis, significado da vida etc.)", no que a Psicologia Positiva opera. Nesse sentido, nosso interesse em pesquisar sobre aplicações da Psicologia Positiva à Educação, emergiu do mal-estar vivenciado pelos docentes. Nesse mesmo sentido, o trabalho de Wandscheer (2012) destaca a importância de reconhecer causas e sintomas do mal-estar, para aumentar as possibilidades de ações visando o bem-estar.

Defendemos que é importante reconhecer causas e sintomas do mal-estar para aumentar as possibilidades interventivas, lembrando de quando Paula (2007) lista alguns estímulos ameaçadores ao professor como forma de buscar estratégias em Educação, mormente o docente queimado (no sentido de burnout). Esses profissionais manifestam sensações de baixa realização pessoal, de autoestima, fracasso e depressão, diminuindo o nível de atuação. A excessiva responsabilidade educativa, a falta de respeito dos discentes e também entre os próprios professores (falta de companheirismo) são alguns dos estímulos que o organismo adverte como ameaçadores. Diante disso, os resultados aparecem no corpo, através de manifestações físicas e psíquicas (estado de ânimo triste, menor capacidade de atenção e concentração, etc.).

Foi nesse sentido que surgiu nosso interesse em pensar na aplicação da Psicologia Positiva ao contexto educacional. Além da excessiva responsabilidade educativa, mesmo de uma da falta de respeito por parte dos alunos e de falta de companheirismo de alguns colegas, ressaltamos ainda a excessiva demanda de trabalho burocrático, a questão da desvalorização profissional do docente, a carga horária (que pode ser de vinte horas, no entanto com atividades complementares é um tempo bem maior) e, sobretudo, o baixo salário (por exemplo, não recebendo o piso garantido por lei; aumentando sua demanda de atividades sem compensações).

Quando mencionamos o interesse na prevenção e/ou atuação em favor do bem-estar, é no sentido de utilizar estratégias que previnam esse mal-estar, diminuindo seus sintomas. Paula (2007) complementa que há muito parece ter se tornado moda falar de mal-estar entre os docentes e do estresse a que os mesmos estão submetidos, mas que, no entanto, poucos pesquisadores têm tentado ir mais adiante e falar da sintomatologia depressiva que tem sido a raiz 
das baixas laborais e dos problemas físicos e emocionais que mais padecem os professores. A autora ainda afirma que esse "distrés laboral" merece atenção e pesquisas aprofundadas, já que não é algo que aparece repentinamente, mas sim que é fruto de um processo e que cada vez mais se tem notado em profissionais da educação, podendo, em casos mais graves, derivar em transtorno depressivo.

Além disso, destacamos que é difícil, em meio a tantas tarefas docentes, ter ainda reflexões aprofundadas e um olhar atento e minucioso para evitar esses momentos estressores. Nesse sentido, a aplicação da Psicologia Positiva ao campo da Educação vem no sentido de prevenção, de atuar antes de começar esse mal-estar, com o objetivo de poder atuar com antecedência, evitando o contato com fatores estressores e potencializando qualidades e virtudes positivas. Pensemos na atuação também após o docente já estar com mal-estar, em que a atuação é para a diminuição do mesmo a níveis controláveis e não mais tão 'nocivos'. Nesse sentido (de prevenção e/ou intervenção), Seligman (2009, p. 15) defende:

As experiências que induzem emoções positivas fazem as emoções negativas se dissiparem rapidamente. As forças e virtudes, como veremos, funcionam como um parachoque contra a infelicidade e as desordens psicológicas, e podem ser a chave da resistência. Os melhores terapeutas não curam simplesmente os sintomas, eles ajudam a construir forças e virtudes.

Para o autor (2011, p. 37) relaciona o objeto bem-estar à Psicologia Positiva, afirmando que quando na teoria da felicidade autêntica, a Psicologia Positiva objetivava aumentar a quantidade de felicidade na vida das pessoas e do planeta, já "na teoria do bem-estar, em contrapartida, o objetivo da Psicologia Positiva é plural e significativamente diferente: é aumentar a quantidade de florescimento na vida das pessoas e no planeta". Portella (2013) em seu livro faz menção às duas teorias apresentadas por Seligman (felicidade autêntica e florescimento) e, fala também de sua teoria, a teoria da potencialização da qualidade de Vida, com a qual ela objetiva o "crescimento e o desenvolvimento harmonioso das pessoas, acompanhado de bem-estar" (PORTELLA, 2013, p. 42).

Nessa direção, seria possível aumentar a quantidade de florescimento na vida dos professores? Entendemos que sim, sendo extremamente necessário para o seu bem-estar pessoal e profissional, além de que os resultados não são evidenciados apenas em docentes, mas inclusive nos seus discentes, que apresentarão melhores rendimentos com professores bem mais motivados para o exercício de suas funções.

Lembrando as palavras de Seligman (2011), é o bem-estar o tema da Psicologia Positiva (não a felicidade). Nesse sentido, felicidade é apenas um aspecto das emoções positivas, sendo as emoções positivas apenas um dos cinco elementos considerados mensuráveis na teoria do bem-estar: emoção positiva (felicidade e satisfação com a vida são aspectos dela), engajamento, relacionamentos, sentido e realização. 
Nesse sentido, “[...] todo o ser humano tem necessidade de valorização positiva, ou auto-estima positiva, no sentido de mais real, e esta é aprendida mediante a interiorização, ou introjeção das experiências de valorização realizadas pelos outros para ela [...]" (MOSQUERA e STOBÄUS, 2006, p. 84). Ou seja, visando o bem-estar, remetemos a Mosquera e Stobäus (2006), que defendem que todo ser humano tem necessidade de ser valorizado positivamente ou de ter autoestima positiva, sendo que isso só pode ser aprendido a partir da interiorização ou introjeção de experiências externas de valorização.Isso demonstra a importância da necessidade de valorização e reconhecimento das pessoas e das suas ações, e complementam que uma autoestima mais realista é um conjunto de atitudes e de percepção avaliativa que a pessoa tem sobre si própria, é uma maneira de ser e de se pensar sobre si, que podem tanto ser positivas, como negativas, demonstrando que não é estático, já que revelase de acordo com acontecimentos sociais, emocionais e psíquico-fisiológicos (psicossomáticos). Com isso, compreendemos que a autoestima é, portanto, maleável e provém de três elementos básicos: as análises pessoais que próprio sujeito realiza sobre si mesmo, como percebe como os outros o veem e como ele acha que os outros o percebem.

Além da autoestima, os autores (MOSQUERA e STOBÄUS, 2006) também sustentam a importância da autoimagem e da autorrealização na vida das pessoas. A autoimagem também aparece como vulnerável no mesmo contexto social. Com isso, remetendo-nos aos docentes, devem ter apoios para que possam desenvolver um bom desenvolvimento pessoal e profissional, através de seus níveis de autoestima, autorrealização e autoimagem mais realistas e, para tanto, é necessário que o meio em que atuam lhes propicie isso, mediante uma constante valorização e reconhecimento.

Nos outros trabalhos relatados acima, Santos (2012) chama a atenção para a importância da importância e coesão da equipe gestora; Zacharias (2012) atribui essa função para além da equipe gestora, para o Estado e para a família, sendo necessário um trabalho conjunto e uma mobilização de todos os envolvidos com a educação para que possamos, de fato, notar resultados. Além do mais, consideramos pertinente o alerta de Wandscheer (2012) para a criação de políticas públicas educacionais que visem um maior cuidado ao ser humano educador. Além disso, achamos importante realizar uma melhor acolhida e manutenção de climas mais positivos com os docentes, como forma de desenvolver melhores e sadios níveis de bem-estar.

Melhorar esses níveis de bem-estar docente não apenas traz um novo sentido a sua vida pessoal e profissional, como pode fazer a diferença para todo o contexto educacional onde atua. Nesse sentido, destacam Mosquera e Stobäus (2006, p. 86), em relação à busca de uma educação (mais) inclusiva, que "[...] o papel de um professor/profissional mais saudável, que tenha melhores relações interpessoais mais sadias, deve, sem dúvida, levar (a si) educandos/ pessoas por ele cuidadas à auto-realização, para chegar a ser e realizar-se e ajudar outros [...]”. 
Já dissemos que docentes com níveis mais realistas/elevados provavelmente terão alunos que aprenderão melhor ao se sentirem motivados e com suas potencialidades reconhecidas.Nesse sentido, o trabalho de Altafini (2012) elenca que a Psicologia Positiva associada à aprendizagem significativa é capaz de contribuir para a reflexão sobre as intervenções mais eficientes, aumentando a motivação dos alunos para aprender. Aliás, os termos "valorização" e "reconhecimento" também são foco da Psicologia Positiva, que trabalha reconhecendo e ressaltando as potencialidades e virtudes humanas.

Como bem diz Seligman (2011, p. 23), “[...] o tema da psicologia positiva é o bem-estar, que o principal critério para a mensuração do bem-estar é o florescimento, e que o objetivo da psicologia positiva é aumentar esse florescimento". Assim, reiteramos, conforme nosso grupo de estudos sobre bem e mal-estar docente, para a importância do reconhecimento do docente como pessoa antes de nos remetermos à sua prática, para depois vermos seu lado profissional. Apesar de existir uma conversa sobre o "dever" de separar a vida pessoal da profissional, comentamos do quão impossível é isso.

Fechamos com Seligman (2011), que coloca que a Psicologia Positiva é capaz de tornar as pessoas mais felizes, e, portanto, a mesma deve ser lecionada, pesquisada e utilizada na prática. $\mathrm{O}$ autor sugere que se ofereçam exercícios de Psicologia Positiva a alunos em sala de aula e que os filhos também sejam criados sob essa perspectiva. Ele também afirma que as pessoas que trabalham com a Psicologia Positiva são as que desfrutam do mais alto bem-estar que ele conhece. Com isso, a sugestão é de que pudéssemos trabalhar com a Psicologia Positiva com docentes, mas também com toda a comunidade acadêmica, quem sabe mesmo saindo da escola, até a família e a própria sociedade. Na perspectiva de Seligman (2011) isso é possível e traz resultados bastante satisfatórios.

\section{Considerações finais}

Reforçamos os comentários de Paula (2007, p. 55) que afirma que "o trabalho pode constituir um objetivo e dar sentido a vida. Pode brindar uma estrutura e um conteúdo ao nosso dia, semana, ano e, inclusive, vida inteira. Pode oferecer-nos identidade, autoestima, apoio social e recompensas materiais". Isso, levando em conta exigências laborais ótimas (e não máximas), um determinado grau de autonomia no que exerce e quando lhe é propiciado um ambiente de trabalho cordial e solidário. Com isso, "o trabalho pode ser um dos fatores favorecedores da saúde mais importantes de nossa vida. Pelo contrário, se as condições de trabalho apresentam os tributos opostos, podem [...] produzir ausência de saúde" ou ainda, no pior dos casos, causar enfermidade, acelerar seu curso ou mesmo desencadear seus sintomas. 
Destacamos uma vez mais que o trabalho docente pode ser promotor de felicidade e bem-estar, principalmente quando exercido com os suportes necessários para sua realização, com exigências que não extrapolem capacidades, carga horária, e que modifiquem níveis de insatisfação e sentimento de incompetência e desvalorização. Mesmo com as poucas pesquisas pudemos detectar resultados bastante significativos, como apresentamos nesse texto. A Psicologia da Saúde e Psicologia Positiva conectam-se bem à Educação, tanto para docentes como para discentes. Consideramos intervenção e prevenção as palavras-chave desse contexto, visando uma maior valorização e reconhecimento do profissional professor. Agindo de forma interventiva e preventiva, preconizamos que a Psicologia Positiva permite fazer com que o docente tenha maior noção da importância do seu trabalho, reconheça-se mais realisticamente e influencie positivamente seus alunos, mais ainda em se tratando de futuros docentes.

\section{Referências}

ALTAFINI, Magda. Estudantes universitários com dificuldades de aprendizagem: como motivá-los?. 2012. 130f. Dissertação (Mestrado em Educação) - Faculdade de Educação. Pontifícia Universidade Católica do Rio Grande do Sul: Porto Alegre, 2012.

CASTILHOS, Daniel Carneiro. Grupo de sensibilização e criatividade: espaço de retomada de bem-estar/autoimagem/autoestima de educadores. 2011. 110f. Dissertação (Mestrado em Educação) - Faculdade de Educação. Pontifícia Universidade Católica do Rio Grande do Sul: Porto Alegre, 2011.

DOHMS, Karina Pacheco. Níveis de mal-bem-estar docente, de autoimagem e autoestima e de autorrealização de docentes em uma escola tradicional de Porto Alegre. 2011. 112f. Dissertação (Mestrado em Educação) - Faculdade de Educação. Pontifícia Universidade Católica do Rio Grande do Sul: Porto Alegre, 2011.

ESTEVE, José M. El malestar docente. 3. ed. Barcelona: Paidós, 1994.

GUTERRES, Rodrigo de Azambuja. Educação física nas séries iniciais: uma proposta de bem-estar para unidocentes do município de Alegrete-RS. 2011. 90f. Dissertação (Mestrado em Educação) - Faculdade de Educação. Pontifícia Universidade Católica do Rio Grande do Sul: Porto Alegre, 2011.

HUÉ, Carlos. Bienestar docente y pensamiento emocional. España: Wolters Kluwer España, 2008.

JESUS, Saul N. de; REZENDE, Manuel. Saúde e bem-estar. In: CRUZ, José; JESUS, Saul N. de ; NUNES, Cristina (Coord.). Bemestar e qualidade de vida: Contributos da Psicologia da Saúde. Portugal: Textiverso, 2009.

JESUS, Saul N de. Professor sem stress: realização profissional e bem-estar docente. Porto Alegre: Mediação, 2007.

KEHL, Urbano. Bem-estar e mal-estar dos professores no Colégio Marista Pio XII de Novo Hamburgo-RS. 2011. 90f. Dissertação (Mestrado em Educação) - Faculdade de Educação. Pontifícia Universidade Católica do Rio Grande do Sul: Porto Alegre, 2011.

MENDES, Aline Rocha. Saúde docente: uma realidade detectada - em direção ao bem-estar e a realização profissional. 2011. 116f. Dissertação (Mestrado em Educação) - Faculdade de Educação. Pontifícia Universidade Católica do Rio Grande do Sul: Porto Alegre, 2011. 
MOROSINI, Marília Costa (Org.). Enciclopédia de Pedagogia Universitária: glossário. Brasília: INEP/RIES, 2006. Vol. 2.

MOSQUERA, Juan J. M.; STOBÄUS, Claus D. Auto-imagem, auto-estima e auto-realização: qualidade de vida na universidade. Psicologia, Saúde \& Doenças, v. 7, n. 1, p. 83-88, jul. 2006.

PAULA, Isabel. ¡No puedo más! Intervención cognitivo-conductual ante sintomatología depresiva en docentes. Madrid: Wolters Kluwer España, 2007.

PINHEIRO, Leandro Brum. O bem-estar na escola salesiana: evidências da realidade. 2011. 141f. Dissertação (Mestrado em Educação) - Faculdade de Educação. Pontifícia Universidade Católica do Rio Grande do Sul: Porto Alegre, 2011.

PORTELLA, Mônica. A ciência do bem-viver: propostas e técnicas da Psicologia Positiva. 2. ed.. Rio de Janeiro: CPAF-RJ, 2014.

PORTELLA, Mônica (Org.). Teoria da potencialização da qualidade de vida: propostas e técnicas da psicologia positiva. Rio de Janeiro: CPAF-RJ, 2013.

SANTOS, Douglas Leal dos. A influência da gestão escolar no bem estar docente: percepções de professores sobre líderes educacionais de uma escola particular de Porto Alegre. 2012. 93f. Dissertação (Mestrado em Educação) - Faculdade de Educação. Pontifícia Universidade Católica do Rio Grande do Sul: Porto Alegre, 2012.

SELIGMAN, Martin E. P. Florescer: uma nova compreensão sobre a natureza da felicidade e do bem-estar. Rio de Janeiro: Objetiva, 2011. SELIGMAN, Martin E. P.. Felicidade autêntica: usando a nova psicologia positiva para a realização permanente. Tradução de Neuza Capelo. Rio de Janeiro: Objetiva, 2009.

SENNA, Lenira Botelho. Do mal-estar ao bem-estar docente: uma análise de caso Argentina e Brasil. 2011. 135f. Dissertação (Mestrado em Educação) - Faculdade de Educação. Pontifícia Universidade Católica do Rio Grande do Sul: Porto Alegre, 2011.

STOBÄUS, Claus D.; MOSQUERA, Juan J. M.; SANTOS, Bettina S. dos. Grupo de pesquisa mal-estar e bem-estar na docência. Educação, Porto Alegre, ano XXX, n. especial, p. 259-272, out. 2007.

WANDSCHEER, Marli Ferreira. Atividades artísticas com teor terapêutico e suas contribuições para a compreensão das inquietações do ser humano professor. 2012. 141f. Dissertação (Mestrado em Educação) - Faculdade de Educação. Universidade do Oeste de Santa Catarina: Joaçaba, 2012.

ZACHARIAS, Jamile. Bem-estar docente: um estudo em escolas públicas de Porto Alegre. 2012. 152f. Dissertação (Mestrado em Educação) - Faculdade de Educação. Pontifícia Universidade Católica do Rio Grande do Sul: Porto Alegre, 2012.

\section{Endereço para correspondência:}

Jordana Wruck Timm

Av. Mal. Floriano Peixoto, 3072

96170-000 São Lourenço do Sul, RS, Brasil

E-mail:<jordanawruck@hotmail.com>

Recebido em: jun./2014

Aceito em: ago./2014 